\title{
HeRMENÊUTICA DE RILKE
}

\author{
Sidney Martins* \\ Universidade Metodista de São Paulo (UMESP) São Bernardo do Campo - SP
}

\begin{abstract}
RESUMO
Franz Xaver Kappus foi um aspirante à poeta que pediu conselhos e sugestões ao renomado escritor Rainer Maria Rilke. Estes pedidos se deram por meio de cartas ao qual Kappus não recebe nenhuma sugestão quanto à estilística, métrica ou composição de poemas, mas sim, vários conselhos na perspectiva de construção de uma obra através das experiências mais singelas da vida. Após o falecimento de Rilke a coleção destas epistolas direcionadas a Kappus foi compilada em um livro, com o sugestivo nome de "Cartas a um Jovem Poeta". Desde então tem servido para muitos leitores como um livro basal ao entendimento pessoal, que versa sobre o pertencimento e de qual é o nosso lugar de atuação no mundo. Essa comunicação tange ao conteúdo dessas cartas, de que cunho são tais conselhos e o fundo filosófico que estes contém; com isso realiza-se uma analise desta emblemática obra do século XX.
\end{abstract}

Palavras-chave: Rilke. Epistolografia. Hermenêutica

\section{INTRODUÇÃO}

René Karl Wilhelm Johann Josef Maria Rilke, melhor conhecido como Rainer Maria Rilke, foi um escritor austríaco voltado aos poemas

* Graduando em filosofia pela Universidade Metodista de São Paulo (UMESP) E:mail: house.martins.sidney@gmail.com 
e as novelas. Ele é amplamente conhecido como um dos mais poetas mais intensamente líricos da língua germânica.Ele escrevia tanto prosas como poemas.

Muitos críticos têm descrito o trabalho de Rilke como essencialmente "místico"; por místico entende-se a descrição feita por Patricia H. Stanley em seu artigo sobre Duino Elegeis, onde ela diz: "Se, no entanto, considerarmos por místico "por ter um significado espiritual ou real da qual não é aparente aos sentidos nem tampouco obvio a inteligência racional," então o trabalho de Rilke é certamente místico". (STANLEY, 2000).

Seus escritos incluem uma novela, uma enorme coleção de poemas e uma grande quantidade de correspondências das quais ele evoca a busca de imagens da qual o foca na dificuldade de comunicação com o inefável, numa época de descrença, solidão e profunda ansiedade. Nestes temas profundamente existenciais tendiam a posicioná-lo como uma figura transicional entre os escritores tradicionais e os modernistas.

Rilke viajou extensivamente pela Europa (incluindo Rússia, Espanha, Alemanha, França e Itália) e, em suas ultimas cartas, se fixou na Suíça - local que foi de suma importância na gênesis e inspiração de muitos de seus poemas.

Enquanto Rilke é mais conhecido pelas suas contribuições a literatura da Alemanha, mais de 400 poemas foram originalmente escritos em francês e dedicados ao Canton of Valais na Suíça. Entre os leitores da língua inglesa, seus trabalhos mais conhecidos incluem as coleções Duino Elegies (Duineser Elegien) e Sonetos a Orfeu (Die Sonette an Orpheus), a novela semi biografica Os cadernos de Malte Laurids Brigge(Die Aufzeichnungen des Malte Laurids Brigg) e uma coleção de dez cartas que foram publicadas postumamente sob o titulo de Cartas a um Jovem Poeta (Briefe an einen jungen Dichter).

No final do século XX seu trabalho encontrou novos leitores e através do frequente uso de suas frases por teólogos da Nova Era, autores de auto ajuda, programas televisivos, outros livros diversos e em filmes. Nos Estados Unidos, Rilke continua entre os poetas mais populares e bem vendidos.

Cartas a um Jovem Poeta (Briefe an einen jungen Dichter) é uma coleção de dez cartas escritas pelo poeta austríaco Rainer Maria Rilke Revista Páginas de Filosofia, v. 8, n. 1-2, p. 87-98, jan/dez. 2019 
(1875 - 1926) endereçadas a Franz Xaver Kappus (1883 - 1966), um oficial cadete de 19 anos, alistado na Academia Militar Theresian em Wiener Neustadt.

Rilke, filho de um oficial do exercito austríaco, tinha estudado na escola preparatória da academia em Sankt Pölten pela década de 1890. Kappus se correspondeu com o autor e poeta de 1902 até 1908, buscando seus conselhos e qualificando seus poemas, e na decisão entre a careira literária ou a carreira militar. Kappus compilou e publicou as cartas em 1929, três anos após a morte de Rilke por leucemia.

Rilke, pelo curso de 10 cartas procede em aconselhar Kappus em como um poeta deveria sentir, amar, e buscar a verdade na tentativa de entender e experienciar o mundo aos seu redor e entrar ao mundo da arte. Tais cartas oferecem insights para os temas e ideias que aparecem no processo de trabalho de Rilke. Tais correspondências foram escritas durante o período crucial do desenvolvimento do seu poema de maior reputação intitulado 0 Livro das Horas e seguido, posteriormente, 0 Livro das Imagens.

Em 1929, Frans Xaver Kappus compilou as cartas que havia recebido de Rainer Maria Rilke que haviam sido escritas entre 1903 e 1908 e publicadas sob o titulo e Cartas a um Jovem Poeta. Curiosamente, Rilke e Kappus nunca se encontraram pessoalmente.

Na introdução da coletânea, Kappus rememora como ele começou a escrever para Rilke. Segundo Kappus, no final de 1902, enquanto estudava na academia militar da Áustria, ele estava lendo as poesias de Rilke. Ele era próximo ao capelão da academia, Horacek, que foi quem notou que Rilke tinha sido seu aluno em anos anteriores. Horacek expressou surpresa ao saber o estudante havia se tornado um poeta e descreveu a Kappus como era o jovem Rilke, magro e pálido, do tipo que demonstrava uma inadequação ao serviço e a vida militar. Rilke não continuou sua educação militar. Ao saber disso, kappus decidiu escrever pedindo conselhos ao poeta.

Quando Kappus escreveu a primeira carta a Rilke ele pediu que o autor providenciasse criticas a sua poesia. Rilke proveu pouco em critica ou sugestões para as melhorias do texto de Kappus. Ao invés disso, Rilke desencorajou Kappus de ler sobre critica e aconselhou-o a confiar em seu próprio julgamento. 
Rilke deu conselhos que inspiraram Kappus na busca que assuntos mais abrangentes da intimidade e da natureza da beleza na arte, tanto quanto a questões existenciais e filosóficas. Os assuntos diretamente pessoais que as cartas de Kappus tinha aparentemente revelado a Rilke; tanto sobre o ateísmo, solidão e escolhas de carreira.

A coleção não incluiu as cartas que Kappus escreveu, embora inclua um soneto que Kappus compôs da qual Rilke enviou de volta manuscrito para "ler as linhas como se elas não fossem suas, e você sentirá no seu interior como elas são muito suas".

\section{A influênCia e Rilke em Kappus}

Kappus era de descendência Húngara, Servia e Romena. Foi apenas coadjuvante na escrita a Rilke, e depois publicando estas cartas, Franz Xaver Kappus foi amplamente esquecido na história. Mesmo expressando hesitação na continuidade de sua carreira militar, Kappus continuou sues estudos e serviu por 15 anos como oficial no exercito Austro-húngaro. Por toda a sua vida, ele trabalhou como jornalista e editor de jornais, escreveu poemas, sketches de humor, contos, novelas e alguns trabalhos, como o roteiro para cinema de sua historia. No entanto, Kappus não conseguiu uma fama duradoura.

\section{As CARTAS}

\begin{tabular}{|c|l|l|l|l|}
\hline & ANO & Mês/Dia & Cidade & País \\
\hline $\mathbf{1}$ & 1903 & Fevereiro, 17 & Paris & França \\
\hline $\mathbf{2}$ & 1903 & Abril, 5 & Viareggio, Pisa & Itália \\
\hline $\mathbf{3}$ & 1903 & Abril, 23 & Viareggio, Pisa & Itália \\
\hline $\mathbf{4}$ & 1903 & Julho, 16 & Worpswede, Bremen & Alemanha \\
\hline $\mathbf{5}$ & 1903 & Outubro, 29 & Roma & Itália \\
\hline $\mathbf{6}$ & 1903 & Dezembro, 23 & Roma & Itália \\
\hline $\mathbf{7}$ & 1904 & Maio, 14 & Roma & Itália \\
\hline $\mathbf{8}$ & 1904 & Agosto, 12 & Borgeby Gard, Flãdie & Suécia \\
\hline $\mathbf{9}$ & 1904 & Novembro, 4 & Furuborg, Jonsered & Suécia \\
\hline $\mathbf{1 0}$ & 1908 & Dezembro, 26 & Paris & França \\
\hline
\end{tabular}

Revista Páginas de Filosofia, v. 8, n. 1-2, p. 87-98, jan/dez. 2019 
Apesar do tom reducionista que o emprego de adjetivos tem em uma analise como essa, foi cabal o uso destes na delimitação do principal assunto e estilo de cada uma das cartas datadas anteriormente. Assim seguem a esta classificação de caráter subjetivo:

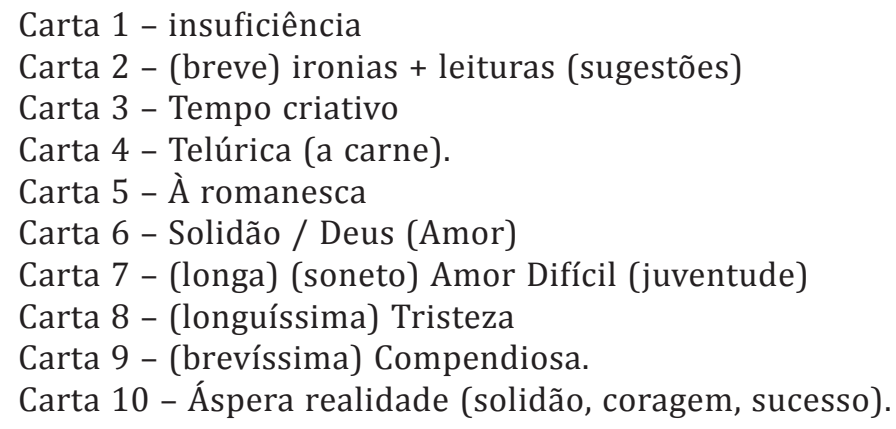

0 conteúdo destas cartas tange questões imanentes à constituição poética não apenas trabalho de Rilke, mas como o de toda a poética germânica em geral. Ressaltando a questão da tristeza como propulsão criativa, onde: "Deve-se experimentar a tristeza (o caráter melancólico), e não viver nela (o pesar depressivo)".

Será decorrido de maneira explanativa, o conteúdo e o pensamento geral de cada missiva.

\subsection{Carta 1 - insuficiência}

A característica mais marcante desta primeira resposta de Rilke à Kappus é a da insuficiência. Esta insuficiência é marcada pela subjetividade na analise critica da própria obra escrita. Rilke estimula ao seu leitor para evitar a opinião de outros sobre sua poesia.

Ao invés disso, o jovem poeta deveria olhar pra dentro e examinar o que verdadeiramente o motivou a continuar escrevendo. Vem desse trecho uma das frases mais emblemáticas de toda a coletânea:

“(...) examine se estende suas raízes pelos recantos mais profundos de sua alma; confesse a si mesmo: morreria, se lhe fosse vedado escrever? Isto, acima de tudo, pergunte na hora mais tranquila de sua noite: "Sou mesmo forçado a escrever?". (RILKE, 2001, p. 26). 
Rilke expande o tema do desenvolvimento de uma vida interior mais rica, o que ofereceria uma perspectiva inspiradora no processo de criação artística.

\subsection{Carta 2 - (breve) ironias + leituras (sugestões)}

Nesta segunda carta, Rilke aconselha o jovem poeta a se afastar das ironias e, no caso de empregar seu uso, fazer com muita cautela: "Não se deixe dominar por ela (a ironia), sobretudo em momentos estéreis. (...) Busque o âmago das coisas, aonde a ironia nunca desce; (...)". (RILKE, 2001, p.32).

Em outra parte de seus conselhos, indica a leitura de duas obras: a Bíblia e "os livros do grande poeta dinamarquês Jens Peter Jacobsen". (p.32) Assim ele continua sua sugestão em Jacobsen:

"Se eu tivesse de confessar com quem aprendi alguma coisa acerca da essência do processo criador, sua profundidade e eternidade, só poderia indicar dois nomes: o de Jacobsen, este poeta máximo, e o de Auguste Rodin, o escultor que não tem igual entre todos os artistas de nossos dias".

(Rilke, 2001, p.33).

\subsection{Carta 3 - Tempo criativo}

A terceira carta tem como tema principal o Tempo Criativo. Rilke explica à Kappus que deve ter um outro foco a sua criação poética. Ele explica que o tempo da construção de um texto é relativo quanto a sua qualidade.

"Deixa amadurecer inteiramente, no âmago de si, nas trevas do indizível e do inconsciente, do inacessível a seu próprio intelecto, cada impressão e cada germe de sentimento, e aguardar com profunda humildade e paciência a hora do parto de uma nova claridade: só isso é viver artisticamente na compreensão e na criação. Aí o tempo não serve de medida: um ano não vale, dez anos não são nada. Ser artista não significa calcular e contar, mas sim amadurecer como a árvore que não apressa a sua seiva e enfrenta tranquila as tempestades da primavera, sem medo de que depois dela não venham nenhum verão. 0 verão há de vir". (RILKE, 2001, p.37). 


\subsection{Carta 4 - Telúrica (a carne).}

0 número quatro tem como simbolismo a representação dos quatro elementos naturais (terra, fogo, água e ar) e,de acordo com o Dicionário de Símbolos escrito por Jean Chevalier e Alain Gheerbrant. “(...) a tétrade pitagórica é produzida pela adição dos quatro primeiros números $(1+2+3+4)$. 0 quatro simboliza o terrestre, a totalidade do criado e do revelado." (CHEVALIER, 2015, p. 759).

Curiosamente, a quarta carta é onde Rilke vai tratar dos prazeres terrenos, o que nos remete a teoria pitagórica à cerca do numero quatro e a teoria do filosofo grego Empédocles sobre os quatro humores.

Rilke ressalta a necessidade de se conhecer empiricamente as vivências, enaltece o enlace amoroso e a mulher, de uma maneira que exalta o ser humano e sua sexualidade a um encontro divinal. Mas faz um alerta sobre o corpo: "A carne é um peso difícil de se carregar" (p. 43). E realça o caráter da memória e da imaginação frente ao empirismo: "A criação intelectual, com efeito, provém também da criação corporal" (p. 44).

Esta carta é uma das mais belas odes a sexualidade que transpassam a lascividade de caráter lacônica.

\subsection{Carta 5 - À romanesca}

Nesta breve missiva, Rilke descreve e reclama da multidão de pessoas que toma Roma e de sua prolixidade. Reclama das ruínas e do mal estado da cidade. Praticamente não abrange conselhos ou sugestões ao trabalho do poeta.

Ao falar da cidade que é considerada um museu a céu aberto, Rilke promulga: “(...) há muita beleza aqui, (...) há também jardins, inesquecíveis alamedas e escadas, escadas imaginadas por Michelangelo, (RILKE, 2001, p. 48).

Mas também relata sua implicância com as multidões, seja de locais ou turistas e o barulho e tumulto que provocam: "Tais impressões fazem com que a gente se recolha e se recupere da pretensiosa multidão que fala e tagarela por toda a parte". (RILKE, 2001, p.48). 


\subsection{Carta 6 - Solidão / Deus (Amor)}

As próximas três cartas são as que aprofundam os pensamentos de Rilke no que tange, sequencialmente, a Solidão, o Amor e a Tristeza. Nesta sexta carta, Rilke escreveu seu texto próximo ao Natal, o que influenciou muito na escolha do tema da Solidão.

"Os seus acontecimentos interiores merecem todo o seu amor; neles de certa maneira deve trabalhar e não perder demasiado tempo e coragem em esclarecer suas relações com os homens. Aliás, quem lhe diz que as tem?". (RILKE, 2001, p.52).

\subsection{Carta 7 - (longa) (soneto) Amor Difícil (juventude)}

Na sétima carta, Rilke agradece o Soneto que o jovem poeta escreveu e reenviou uma cópia manuscrita por ele para que Kappus tivesse a compreensão de como seu texto já começava a ter um estilo próprio. Mas o tema central dessa carta é o Amor, e suas dificuldades. Lembrando o enfoque que ele dá ao amor de juventude e todas as expectativas que se cria nesse amor fulgás e efêmero.

"Sabemos pouca coisa, mas que temos de nos agarrar ao difícil é uma certeza que não nos abandonará. É bom estar só, porque a solidão é difícil. 0 fato de uma coisa ser difícil deve ser um motivo a mais para que seja feita. Amar também é bom: por que o amor é difícil. 0 amor de duas criaturas humanas talvez seja a tarefa mais difícil que nos foi imposta, a maior e última prova, a obra para a qual todas as outras são apenas uma preparação". (RILKE, 2001, p.58).

\subsection{Carta 8 - (longuíssima) Tristeza}

Apesar de Rilke salientar o pouco que tem a explicar a Kappus, "embora quase nada lhe possa dizer de prestimoso, de útil" (p. 65), essa é a mais longa de todas as cartas emitidas ao jovem aprendiz de poeta. 0 tema principal desta epistola é a Tristeza.

Rilke inicia retomando o tema da Solidão: "Falando novamente em solidão, torna-se cada vez mais evidente que ela não é, na realidade, uma coisa que nos seja possível tomar ou deixar. Somos nós" (p.67). 0 que remete aos conselhos dados na primeira carta, em que ele aconselha a retornar a si mesmo e não ouvir críticas externas. Rilke continua 
a aceitar a tristeza, pois dela é possível aprender e constituir melhor a sua subjetividade:

"O "grandioso" não foi aquilo que o senhor pensa ter cumprido (embora seu sentimento tenha razão), mas o fato de já ter existido algo que o senhor pôde colocar em seu lugar daquele engano, algo de real e verdadeiro. Sem isso, o seu trunfo também teria sido apenas uma reação moral, sem significação ampla; com ele, tornou-se uma seção de sua vida. [...] Vejo-a abandonar agora o grande para chegar aos maiores. Eis por que não cessa de ser difícil, mas tão pouco cessará de crescer". (RILKE, 2001, p.71)

\subsection{Carta 9 - (brevíssima) Compendiosa.}

Tecnicamente falando, essa é a última carta de conselhos que Rilke fará ao seu interlocutor Kappus. Rilke faz em duas páginas uma espécie de resumo dos conselhos que já havia promulgado durante o percurso das outras correspondências. 0 tom agora é de um epílogo, dado o caráter de arremate que o autor austríaco traz na escrita.

"Quanto aos sentimentos: são puros todos aqueles que o senhor concentra e guarda; impuros os que agarram só de um lado de seu ser e o deformam. (...) Tudo o que o torna mais do que foi até agora em suas melhores horas é bom." (RILKE, 2001, p.74)

O teor filosófico dessa carta é explicitado sobre a questão da dúvida: "Sua dúvida pode tornar-se uma qualidade se o senhor a educar. Deve-se transformar em saber, em crítica". (p.74) Assim, Rilke sugere a Kappus a manter o questionamento sempre, em uma atitude de se estar sempre atento aos próprios pensamentos e sentimentos, e como estes conduzem o seu agir critico e criativo.

\subsection{Carta 10 - Áspera realidade (solidão, coragem, sucesso).}

Esta última carta é atemporã. Ela foi enviada em 1908, quatro anos depois da intensa troca de correspondência entre Rilke e Kappus. Em tom de celebração, Rilke comemora a maneira como Kappus está encarando agora a vida e como seus conselhos ajudaram o jovem poeta nesse aprendizado. A coragem em relação aos diversos fatos e sentimentos que a vida trouxe até então e como a solidão foi à maneira 
mais eficaz que Kappus conseguiu aprender sobre si, a como agir sem influencias externas, a como ouvir seus impulsos e saber dosar suas ações diante dos acontecimentos.

Ao qual remete a ideia de sucesso, dado que o jovem poeta já teria a habilidade de expressão pessoal e a construção de uma autocrítica capaz de discernir entre quais de seus textos seriam bons de publicar, quais seriam extremamente pessoais, e quais não estariam bons ou prontos o suficiente.

Tende-se a imaginar quão imaginativa e expansiva era a obra de Kappus. Mas infelizmente o jovem poeta não escreveu nada da qual a historia da literatura tenha dado importância, sendo que sua biografia estará sempre conectada nesta compilação das cartas de velho poeta Rilke.

"A arte também é apenas uma maneira de viver. (...) Estou contente, numa palavra, de ver que o senhor resistiu à tentação de cair nelas e está vivendo no meio de uma áspera realidade, solitário e corajoso". (RILKE, 2001, p.76-7).

\section{Correlações com a Hermenêutica do Sujeito}

Os conselhos de Rilke remetem aos ensinamentos entorno do cuidado de si, tema da compilação das aulas de 1982 de Michel Foucault. Aspectos inerentes aos cuidados com a alma prescritos por Sócrates, Epicuro, Sêneca e Epicteto são recorrentes na perspectiva do poeta a seu discípulo missivista. “a) Inicialmente, uma função crítica. (...), b) Tem também uma função de luta. (...), c) Sobretudo, essa cultura de si tem uma função curativa e terapêutica" (2010, p.446-7 ).

Outra parte do resumo de seu curso, Foucault explica: "Ora, de que precisamos para poder manter nosso domínio diante dos acontecimentos que podem produzir-se? Precisamos de "discursos": lógoi, entendidos como discursos verdadeiros e discursos racionais". (FOUCAULT, 2010, p.). A sequência onde explica os exercícios e práticas dos cuidados de si também se assemelham ao grupo de conselhos dados por Rilke em torno da solidão, do entendimento do tempo, da necessidade de ação e do trabalho do escritor. 
A sequência que se demonstra assertiva, portanto, para uma analise das cartas de Rilke à Kappus está presente em uma das últimas aulas de 1982, onde Foucault decorre sobre a arte de viver: "Isso significa que vemos aparecer, creio, a ideia fundamental de que a vida deve ser reconhecida, pensada, vivida praticada como uma perpétua prova". (2010, p. 393). É possível destacar ainda alguns pontos que aprofundam os ditames dessa pratica de vida. Foucault rememora: "Primeiro, a ideia de que a vida, a vida com todo o seu sistema de provas e de infortúnios, a vida por inteiro, é uma educação". (2010, p. 395).

Esse trecho nos levam aos pensamentos que Rilke expõe em sua Carta 1, 6 e 8; onde aconselha Kappus a enfrentar suas tristezas, compreendê-las e encontrar em si as palavras que expressem melhor suas melancolias, seus dissabores, suas frustrações, e eleve seu texto à algo que lhe pertença e, assim, desnude-o. Outro ponto que Foucault ressalta é que:

Em segundo lugar, a generalização da prova como vida, ou ainda a ideia de que o cuidado de si deve atravessar toda a vida, na medida em que a vida deve ser consagrada inteiramente à formação de si mesmo, (...). A Vida como prova é reservada, é feita para as pessoas de bem. (2010, p. 395).

Por pessoas de bem se entende aquelas que não estão pressas aos prazeres nem a obtenção de glorias. Reforçando o conteúdo de Rilke nas Cartas 4 e 9, onde é explicado o valor dos prazeres como experiências humanas possíveis e desejáveis e não algo a que se deva cultivar tal como um vício.

Foucault cita, do texto de Epicteto, sobre a figura do explorador, sendo este aquele homem que "são tão virtuosos por natureza, (...) que o Deus (...) envia-os como exploradores para os maiores perigos, as maiores dificuldades". (2010, p. 396).

Do que vai se chamar aqui de filósofo-explorador, e da qual e capaz de se amplia tal ideia a de um poeta-explorador, é possível, portanto, elucubrar qual seria a visão de Kappus sobre Rilke: “(...) exploradores que cumpriram seu contrato, conquistaram a vitória, e capazes de ensinar aos outros que é possível triunfar sobre as provas e males, e que há para isso um caminho que eles podem ensinar" (2010, p. 396). 
Rilke é um paradigma da qual Kappus almejou alçar um patamar de proximidade e equidade, o que não conseguiu ao menos em âmbito público. Mas nos deixou o legado dos conselhos do poeta-explorador austríaco, que de certo serviu e servirá como base para muitos aspirantes às letras.

\section{REFERÊNCIAS}

CHEVALIER, Jean; GHEERBRANT, Alain. Dicionário de Símbolos. Editora José Olympio: São Paulo, 2015.

FOUCAULT. Michel. A Hermenêutica do sujeito. WMF Martins Fontes: São Paulo, 2010. STANLEY, Patricia H. Rilke's Duino Elegies: An Alternative Approach to the Study of Mysticism" In Heep, Hartmut (editor) Unreading Rilke: Unorthodox Approaches to a Cultural Myth. Peter Lang. New York, 2000.

RILKE, Rainer Maria. Cartas a um jovem poeta. Editora Globo: São Paulo, 2001. 